\title{
A PROTOCOL FOR THE LONGITUDINAL ASSESSMENT OF PATIENT-REPORTED OUTCOMES AT A LARGE COMPREHENSIVE CANCER CENTRE IN AUSTRALIA
}

Gemma Skaczkowski ${ }^{1,2}$ \& Carlene Wilson ${ }^{1,2}$

${ }^{1}$ School of Psychology \& Public Health, La Trobe University

2 Olivia Newton-John Cancer Wellness \& Research Centre, Austin Health

\section{BACKGROUND}

1. Distress is the $6^{\text {th }}$ vital sign in cancer care and a significant burden for many cancer patients. ${ }^{1}$

2. Tracking experiences of care over time will allow us to identify antecedents and correlates of distress across the cancer pathway.

3. The Olivia Newton-John Cancer Wellness \& Research Centre (ONJ Centre) is a comprehensive cancer treatment centre in Melbourne, Australia. The ONJ Centre provides access to a range of supportive care programs and resources.

\section{METHODS}

PARTICIPANTS: All cancer patients, aged 18+ years, who attend the ONJ Centre for diagnosis and/or treatment and are able to participate unaided.

\section{PROCEDURE}

1. Survey advertised to all patients attending the ONJ Centre through their primary clinical contact. Also advertised through posters in waiting areas and pamphlets in information packs.

2. Patients directed to a website to complete the survey online.

3. Email reminders to complete subsequent surveys at:

- 1 month post-diagnosis

- 3 months post-diagnosis

- 6 months post-diagnosis

- 1 year post-diagnosis

\section{MEASURES}

Key measures are shown in the Table.

Questions asked in the context of the last 7 days
AIMS: to conduct a pilot feasibility study for the longitudinal assessment of patient-reported outcomes:

1. To identify mental well-being, quality of life, and symptom burden of cancer survivors attending the ONJ Centre.

2. To examine changes in these outcomes over time.

3. To examine the impact of supportive care interventions.

\section{CHALLENGES}

1. Feasibility of, and procedure for, recruiting all cancer patients attending the ONJ Centre.

2. Appropriate and available software?

3. Process for managing patient distress identified through the survey.

4. Confidentiality and privacy.

\begin{tabular}{l|l|} 
CONSTRUCT & MEASURE \\
\hline $\begin{array}{l}\text { Symptom severity } \\
\text { and distress }\end{array}$ & $\begin{array}{l}\text { Edmonton Symptom Assessment System } \\
\text { PCOC Symptom Assessment Scale }\end{array}$ \\
\hline $\begin{array}{l}\text { Anxiety and } \\
\text { depression }\end{array}$ & Hospital Anxiety and Depression Scale \\
\hline $\begin{array}{l}\text { Quality of life \& } \\
\text { fatigue }\end{array}$ & FACT-G \& FACIT-F \\
\hline $\begin{array}{l}\text { Post-traumatic } \\
\text { stress }\end{array}$ & Impact of Event Scale - Revised \\
\hline $\begin{array}{l}\text { Social well-being } \\
\text { IIIness } \\
\text { representation }\end{array}$ & $\begin{array}{l}\text { Cancer Loneliness Scale } \\
\text { Revised }\end{array}$ \\
\hline Coping style & Brief-COPE \\
\hline
\end{tabular}

